\title{
Olaf Meyer
}

\section{Korruption im Vertrag}

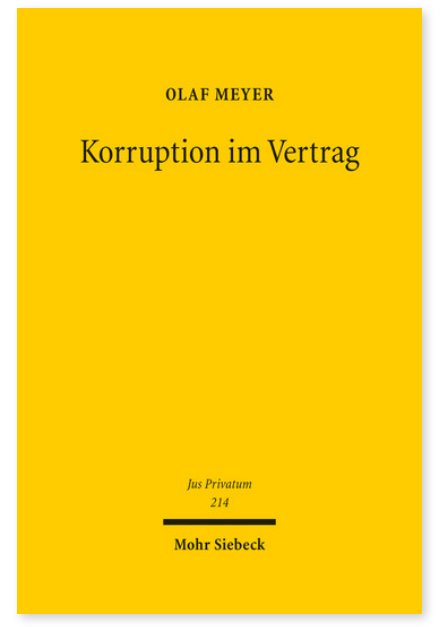

2017. XXVI, 495 Seiten. JusPriv 214

ISBN 978-3-16-154708-9

DOI 10.1628/978-3-16-154708-9

eBook PDF 129,00€

ISBN 978-3-16-154707-2

Leinen $129,00 €$
Die effektive Bekämpfung der Korruption hat sich in den letzten Jahren als rechtspolitisches Dauerthema etabliert. Im Mittelpunkt stand dabei bislang der Ausbau von Strafvorschriften, im zunehmenden Maße aber auch die boomende Compliance-Branche mit ihren zahlreichen neuen Anforderungen an die Unternehmensorganisation. Demgegenüber ist die Rolle privater Klagen in diesem Zusammenhang bislang nur wenig untersucht worden, obwohl in anderen Rechtsbereichen wie dem Kartell- oder dem Umwelthaftungsrecht die Diskussion um das »private enforcement« schon weit vorangeschritten ist.

Vor diesem Hintergrund untersucht der Autor die zivilrechtlichen Folgen von Bestechungszahlungen, namentlich die rechtliche Durchsetzbarkeit der betroffenen Verträge, die Möglichkeiten zur Gewinnabschöpfung und die Pflicht zum Schadensersatz. Rechtsökonomische und rechtsvergleichende Betrachtungen runden die Untersuchung ab.

Olaf Meyer Geboren 1973; Studium der Rechtswissenschaft in Münster und Oxford; 2007 Promotion; seit 2006 Wiss. Mitarbeiter und Habilitand an der Universität Bremen; Lehrstuhlvertretungen an der Freien Universität Berlin und der Universität Mannheim.

\section{Jetzt bestellen:}

https://mohrsiebeck.com/buch/korruption-im-vertrag-9783161547089?no_cache=1

order@mohrsiebeck.com

Telefon: +49 (0)7071-923-17

Telefax: $+49(0) 7071-51104$ 